\title{
Tales of a plant twitcher
}

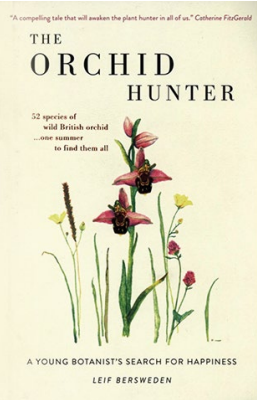

\author{
The Orchid \\ Hunter: A Young \\ Botanist's Search \\ for Happiness
}

By L. Bersweden

SHORTBOOKS UK:

2017. 363 PP. $€ 12.99$.

or readers unfamiliar with the term, twitchers are people traditionally considered to be in constant pursuit of adding new species of birds to their personal lists. With their intelligence network, twitchers are ready to take off at any time of the day or night to travel large distances to see a bird. Twitching is extremely competitive, as the aim is to have the longest list of species seen over a single year, or the highest proportion of rare species. Twitchers are therefore usually highly stressed. The very mention or sight of a rare finding sends them into a fit: they literally twitch, hence their nickname.

Twenty-three-year-old Leif Bersweden, author of The Orchid Hunter, here expands the concept of twitching from bird-watching to botanizing. He shows all the symptoms of a true twitching syndrome, describing himself for instance 'in full plant-hunting mode' when feverishly following directions hastily scribbled down on a note that directed him into the reception area of the Salisbury District Hospital Grounds to find a few flowering Bee orchids on the premises, scrambling around in a nearby nature reserve in search of Burnt orchids in a jacket and tie after having sneaked away from his mother's 50th birthday party, or declaring that while many people can look at a plant for 10 seconds or some for 5 minutes, only very few can do so for hours.

Fortunately, there is also a huge difference between the author of this book and traditional bird twitchers. Where exhausted migrant birds, blown off course by a heavy storm, are unable to feed and therefore often die because they are surrounded by hundreds of twitchers for days in a row, all trying to obtain a photograph of their new species like a horde of press journalists, Bersweden treats the subjects of his pursuit with more respect. The orchids found by him are not trampled on during his photographing sessions but, on the contrary, accompanied by an attention-grabbing twig or pole to warn other botanists of their presence. When he accidently stumbles on the secret locality of the Holy Grail of orchid enthusiasts - the Lady's slipper orchid, of which only a single original individual survives in the wild in the British Isles today so that it is under round-the-clock surveillance by the National Trust - he does not offer the warden any bribes for a closer look such as money, whiskey or Wimbledon tickets.

It is precisely entertaining details such as those described above that make this book a true joy to read. And I must admit that this actually came as a bit of a surprise. Why? Well, over the past 20 years, I discovered that there are generally two types of orchid enthusiasts, or, in the words of the author, 'orchidophiles'. They either suffer from orchid fever from a very young age, as was Bersweden, or were caught by the bug at a much later age, like myself. Orchidologists from the first category definitely have an initial head start in the field, but the drawback is that this often results in a handicap in the long term in that they keep citing rather outdated information that everybody already knows, boring orchidologists from the second category to death, while at the same time preventing modern insights from spreading. An example of the latter is the information provided on salep, a beverage made from the ground tubers of the Early-purple orchid. According to the author, this drink was only made in Europe before the arrival of tea and coffee in the 1700s. Owing to the current revival of authentic foods, however, this is unfortunately far from true. Nowadays tons of orchid tubers of many different species are again being harvested for salep production - a very worrying trend that is now causing many local populations of terrestrial orchids to go extinct throughout the Mediterranean area and beyond. Spreading the outdated message that this is only a practice from the past certainly does not help to raise awareness about the consequences of this very unsustainable plant use.

Another flaw is the rather simplistic view provided on the question of why orchids developed such complex reproductive strategies, which include sexual deception rather than sticking with more straightforward mechanisms that involve nectar rewards like most plant families. The author optimistically states that it has taken years, but that evolutionary biologists have provided answers to all these questions. We indeed now know that orchids deceive their pollinators by, for instance, mimicking female insects, brood sites, food or prey, but we are still far away from understanding how they do this, so asserting that we have answered all questions on this particular topic can be considered premature.

Despite these shortcomings, the witty and lively descriptions of both the 52 individual orchid species tracked down over the course of the story, their original discoverers, the meaning of their scientific and local names and their surrounding landscapes, together with all the blood, sweat and tears that it took the author to see them all in flower in a single season, make this book a very good present for plant lovers.

What I also liked very much is that more controversial topics are not shunned. For instance, Bersweden clearly expresses his frustration about people with a passion for plants always being type-cast as either wasting their time on trivial things or being effeminate or gay. The author makes a passionate plea for taking botany more seriously again by appreciating it as one of the natural sciences and accepting the natural world around us as a fundamental part of being ourselves regardless of gender or sexual preference. I applaud the author for addressing this topic, being criticized myself by some of my family members who wondered out loud 'who on Earth would be interested in reading this' after my first publications on orchids came out. This did not deter me from remaining a botanist, but the number of young people interested in plants is dwindling rapidly all over the world so it is very important to improve our image with books like The Orchid Hunter.

I therefore hope that this book will motivate many others to spend their 'gap year' between high school and further education, a former and a future job or a last job and retirement to take up botanical twitching and see all the plants of their interest in a single year. Those living in the tropics will have to deal with many more orchid species than Bersweden, of course, but they can lay their Orchidelirium to rest with more months of plant hunting as their season is not limited to the spring and summer. And once you are done with the orchids, or do not care for these overmuch, there are myriad rare bulbs, carnivores, cacti, palms, trees or other interesting plants to twitch. Birdwatchers have already written many books about their passion. The Orchid Hunter answers a need for books on botanical twitching and I hope that many others will follow.

\section{Reviewed by Barbara Gravendeel}

Published online: 5 December 2017 https://doi.org/10.1038/s41477-017-0071-z 